\title{
Metal foaming by powder metallurgy process: investigation of different parameters on the foaming efficiency
}

\author{
Ioannis Papantoniou \\ School of Mechanical Engineering, Manufacturing Technology Section, National Technical University of Athens, Greece \\ ipapanto@central.ntua.gr
}

Helena P. Kyriakopoulou, Dimitrios I. Pantelis

School of Naval Arcbitecture and Marine Engineering, Shipbuilding Tecbnology Laboratory, National Technical University of Athens, Greece

kyriakopoulou.elena.alexia@gmail.com

pantelis@central.ntua.gr

Dimitrios E. Manolakos

School of Mechanical Engineering, Manufacturing Technology Section, National Technical University of Athens, Greece manolako@central.ntua.gr

\begin{abstract}
Aluminium foams, produced by powder metallurgy process, have significant potential applications for uses in weight-sensitive structural parts. Problems in the production of metal foams arise from the lack of knowledge in the control of process parameters. The results are frequently uneven and unpredictable variations in the structure and properties of the final foamed parts are observed. This paper aims to investigate the effect of different parameters of the powder metallurgy with foaming agents process on the foaming efficiency. The parameters examined included the powder morphology, the compaction pressure and the foaming temperature. During the foaming stage, for each set of parameters the porosity-time $\left(\mathrm{P}_{\mathrm{f}-\mathrm{t}}\right)$ diagrams were created and the foaming efficiency was calculated $\left(\eta=\mathrm{P}_{\text {fmax }}\right)$. Results indicated that the highest foaming efficiency was observed at the specimens with the fine aluminium powder, with high $(700 \mathrm{MPa})$ compaction pressure and high foaming temperatures $\left(800{ }^{\circ} \mathrm{C}\right)$. Finally, compression tests were performed on the foamed specimens with the higher foaming efficiency in order to investigate their s-e response. Furthermore, average compressive strength and density were estimated and presented.
\end{abstract}

KEYWORDS. Aluminium foam; Foaming process; Foaming efficiency; Mechanical properties; Porosity.

\section{OPEN ACCESS}

Citation: Papantoniou, I.G., Kyriakopoulou, H.P., Pantelis, D.I., Manolakos, D.E., Metal foaming by powder metallurgy process: investigation of different parameters on the foaming efficiency, Frattura ed Integrità Strutturale, xx (2019) 497-504.

Received: 17.01.2019

Accepted: 15.05.2019

Published: 01.10.2019

Copyright: (C) 2019 This is an open access article under the terms of the CC-BY 4.0, which permits unrestricted use, distribution, and reproduction in any medium, provided the original author and source are credited. 


\section{INTRODUCTION}

$\mathrm{M}$ odern-day research in engineering and material science is focused on developing new composite and hybrid materials for the purpose of producing structural elements of lower density and equal or even higher performances. Cellular and microcellular materials are among a new class of materials and are found in everyday uses for their high stiffness, low specific weight and other properties. Applications range from light-weight construction and packaging, to thermal insulation, vibration damping, and chemical filtration [1]. Metallic cellular materials, namely metal foams, merit the use of cellular materials and are becoming a new very promising class of engineering materials. Metal foams offer unique properties, compared to solid metals. Such unique properties are their high strength to weight ratio, high energy absorption capacity, large specific surface, high gas and liquid permeability, and low thermal conductivity [2].

Metal foams serve in a variety of applications, some of which are based on significant mechanical properties (mainly closed-cell foams), while others are based on rheological characteristics and transport processes, made possible by the accessibility of open pores to the ingress and flow of fluid (open-cell foams). The unique properties of foams offer promise in a variety of applications ranging from lightweight construction and impact-energy absorption to various types of acoustic damping and thermal insulation. Areas of applications of those type of materials are the naval industry, aerospace, mechanical or chemical engineering and can be used as heat exchangers, energy or sound absorbers, filters and implants in medicine. The applications of metal foams depend on their basic characteristics such as relative density, cell structure, wall thickness, strut integrity and cell morphology homogeneity [3, 4]. The most common type of stochastic metallic foam is the aluminium foam which is widely preferred due to its important mechanical and natural properties. Two of aluminium foam main characteristics are recyclability and non-toxicity which are numbered among the many benefits. Low density is the most important virtue of aluminium foam because of its light-weight metal structure $[5,6]$.

Aluminium foam production routes are classified into four main groups: powder-metallurgy route, foaming of molten metal, metallic deposition, and sputter deposition. Each one gives its own characteristic range of densities, cell sizes and shapes [7]. In powder metallurgy route, metallic powder is mixed with a blowing agent and it is compacted to form a foamable precursor. Then the precursor is heated and formed in a furnace $[8,9]$. This production process is not as widely used as the lessexpensive molten-metal foaming process, but it also has advantages. The most important advantage of this route is that the precursor can expand in a heated mould and the foam with a complicated shape can be made by mould filling [10].

Worldwide, there is a significant number of ongoing research projects aiming at cheaper and more standardized production of metal foams with high standards, because of their ever-increasing applications [11-13]. The objective of this research is the production of metal foams using powder metallurgy route (with foaming agents) in order to further study and analyze the effect of different parameters in the foam's final porosity and internal structure. The powder metallurgy foaming process has many parameters that may affect the final result (foaming efficiency and pore morphology). The present research aims to obtain the optimum parameters in order in the next phase of this research to use these parameters to study the effect of introducing different types of reinforcing particles in the aluminium foam matrices. Thus, the main parameters examined were the powder morphology, the compaction pressure and the foaming temperature.

\section{EXPERIMENTAL PROCEDURE}

\section{Materials}

7 he powder metallurgy foaming process was applied in our research work. Thus, different type of aluminium powders were applied at the precursor manufacturing process. More specifically, the base materials used were fine aluminium powder (325 mesh, 99.5\%), coarse aluminium powder $(-40+325$ mesh, 99.8\%) and aluminium flakes (APS 11 micron, 99.7\%). Commercially available titanium hydride powder with particle diameter smaller than $45 \mu \mathrm{m}$ was used as a foaming agent $\left(\mathrm{TiH}_{2},-325\right.$ mesh, 99\%). All the powders were purchased from the Alfa Aesar company.

\section{Aluminium Foam Manufacturing Process}

As already mentioned, in this study three aluminium powders with different particle geometries were used. In all cases, the metallic powder was mixed with mass fraction $0.6 \%$ of $\mathrm{TiH}_{2}$ powder in a powder mixer for an hour. Ten grams of each mixture was compacted cold, using an uniaxial compaction, in a 25 -mm-diameter, lubricated, tool-steel die with pressures in the range from $200 \mathrm{MPa}$ to $1200 \mathrm{MPa}$ to achieve different precursor green densities. The green densities were calculated by assuming that the density of the base metal is $2.7 \mathrm{~g} / \mathrm{cm}^{3}$. The precursor specimens were later led to a furnace, so as the foaming procedure to take place under high temperatures (Fig.1). For each combination of aluminium powder and compaction pressure four discrete foaming temperatures were used: $650{ }^{\circ} \mathrm{C}, 700{ }^{\circ} \mathrm{C}, 750^{\circ} \mathrm{C}$ and $800{ }^{\circ} \mathrm{C}$. 
Air-atomized Al powder
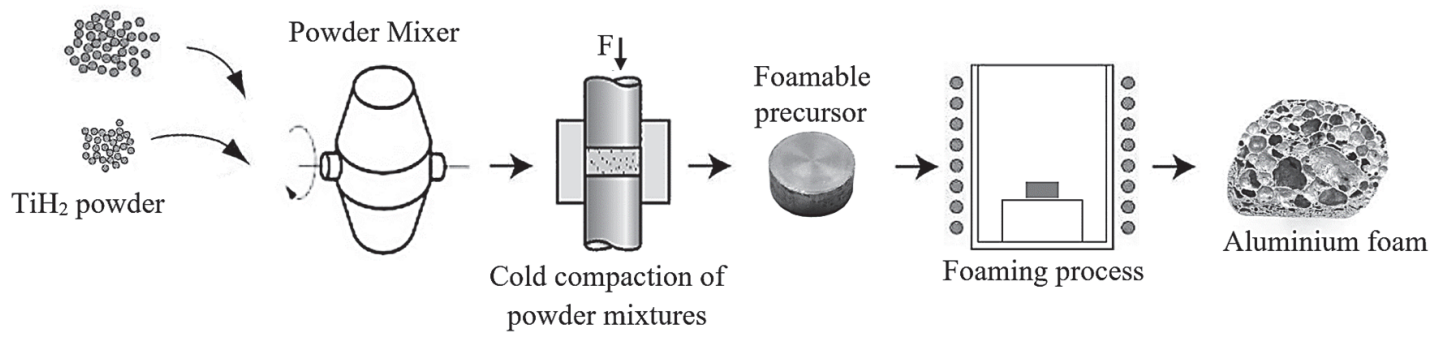

Figure 1: Powder metallurgy route Al foam manufacturing process.

Foaming Process

An especially designed setup was used to characterize the free expansion behaviour of the precursors during the foaming stage. The setup consisted a ceramic-glass window at the front side of the furnace and a high definition camera mounted at a close distance behind the glass. The camera was connected to a computer for recording images (at a rate of 60 frames per second). Using this setup, we were able to monitor the foaming process in al the experiments. The foaming time used was 10 minutes in order to observe all the foaming stages. The basic stages of the foaming process as seen in Fig. 2 are the nucleation and growth, the peak, the pore coarsening and finally the porous structure decay.
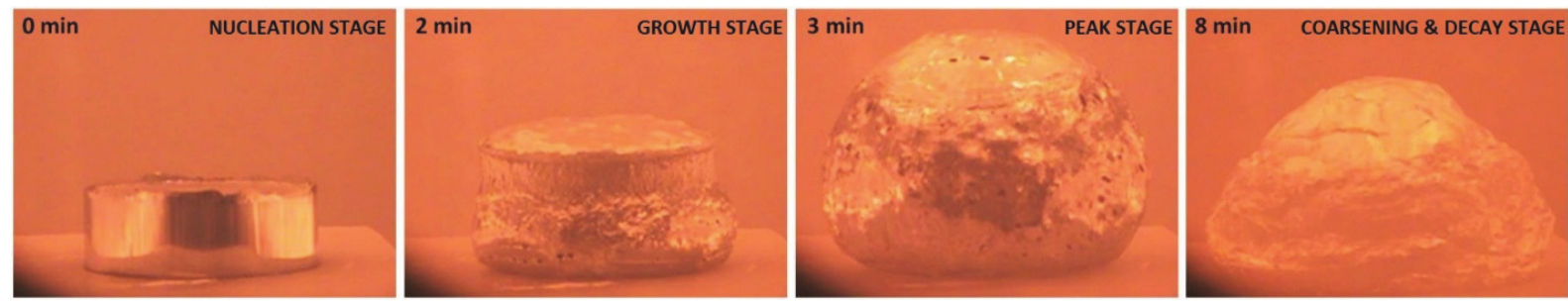

Figure 2: Main stages during the foaming process (nucleation, growth, peak, coarsening and decay).

By analyzing the data from the camera using the open-source image processing software ImageJ, we were able to create the porosity-time $\left(\mathrm{P}_{\mathrm{f}_{\mathrm{t}}}\right)$ diagrams for each specimen by using an image analysis procedure (Fig.3). The procedure included application of median edge preserving filters and special area detecting tools. Volume expansion was estimated by calculating the change of the solid precursor to quasi-spherical shape (liquid foam state). Hence, the porosity $\left(\mathrm{P}_{\mathrm{f}}\right)$ and the foaming efficiency $\left(\eta=\mathrm{P}_{\text {fmax }}\right)$ was quantitatively expressed by the measure of macroscopic volumetric expansion. The porosity and the foaming efficiency were evaluated based on the relative volume of the obtained foam $\left(\mathrm{V}_{\mathrm{r}}\right)$, calculated by dividing the initial volume of the aluminium precursor $\left(\mathrm{V}_{\mathrm{i}}\right)$ to the final volume of the foamed specimen $\left(\mathrm{V}_{\mathrm{f}}\right)$. Thereof, the porosity and the foaming efficiency were expressed as Eq.(1):
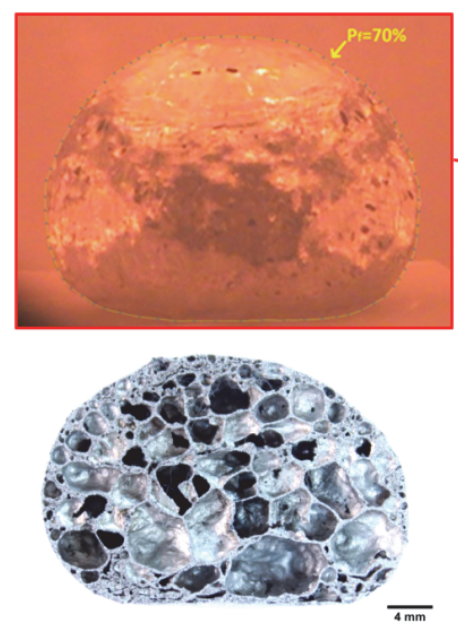

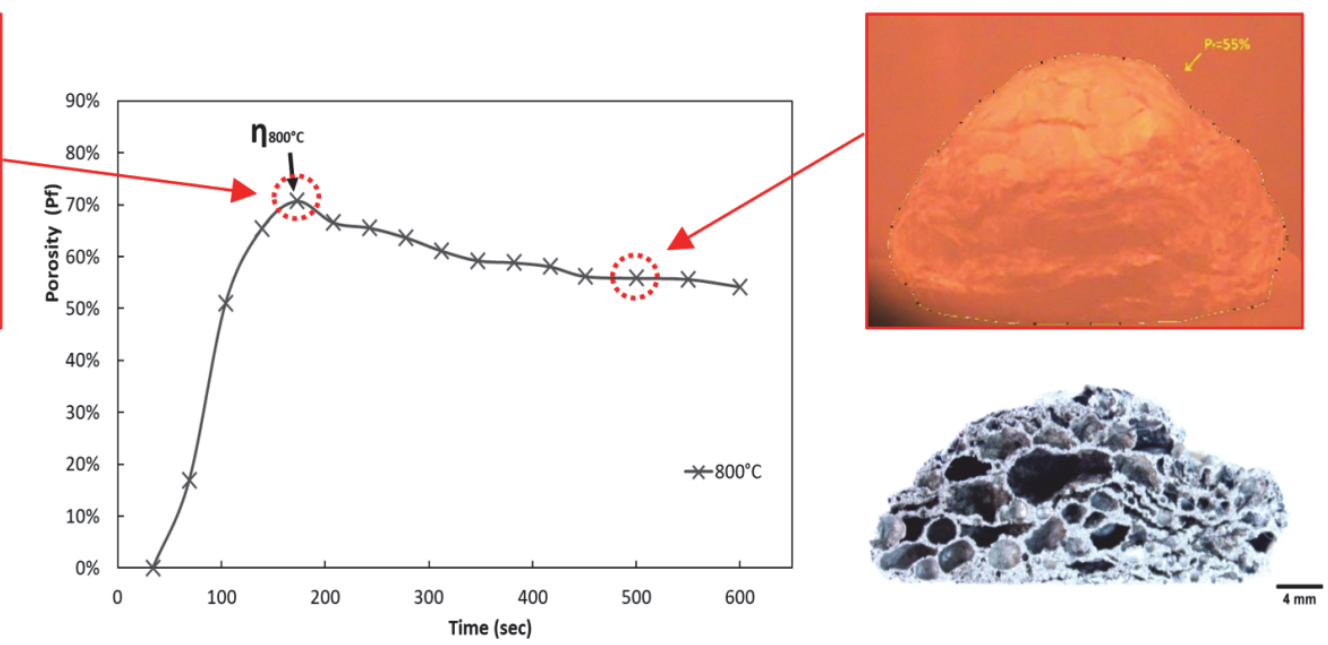

Figure 3: $\mathrm{P}_{\mathrm{f}}-$ Time diagram and foaming efficiency $(\eta)$ calculation using open-source image processing software ImageJ and Al-foam cross-sections at the peak and decay stages (corresponding to 180 and 500 seconds respectively). 


$$
P_{f}=1-V_{r}=1-\frac{V_{i}}{V_{f}}, \eta=P_{f m a x}
$$

Furthermore, specimens were created at different typical foaming times (e.g. peak, decay) in order to examine the porous structure. Cross-sections of the specimens were cut using Discotom ${ }^{\circledR}$ cut-off machine and processed by Electro Discharge Machining $(\mathrm{EDM})$ to visualize the interior structure, without introducing any smearing effects in the surface. Surface smearing occurs due to collapsing of the cell walls brought about by machining forces, which is also dependent on pore size and shape of individual cells. Fig.4a shows the smearing effect caused by machining of metal foam and Fig.4b shows the other half of the specimen after surface processing using EDM.
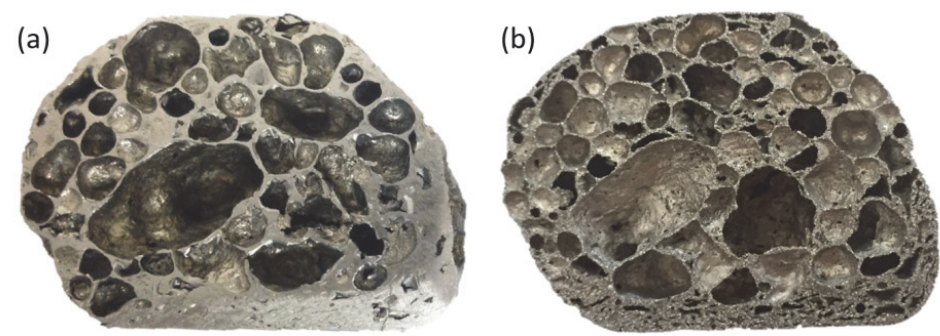

Figure 4: Stereoscopic images of $\mathrm{Al}$ foam cross-section: a) after machining using a metallographic cutting machine, b) after EDM process.

\section{Compressive Properties}

In order to analyze the foam's mechanical properties specimens were manufactured and submitted to uniaxial compression. Thus, six additional specimens with the optimum parameters (parameters that led to maximum foaming efficiency) were manufactured and foamed at a holding time which corresponded to the maximum porosity (peak). Electrical Discharge Machining (EDM) was used to extract the samples out of the foamed batch and to create specimens of specific geometry (20 mm diameter, $20 \mathrm{~mm}$ height). Tests were performed in a universal testing machine (Instro 4482) at room temperature and ambient air and with a constant crosshead speed of $5 \mathrm{~mm} / \mathrm{min}$. The samples were compressed to $70 \%$ strain. The machine's axis was parallel to the direction of the compression axis and the samples were placed on the steady press base. A preload was applied to the samples until the gaps between the sample and jaws disappeared. From the load-displacement acquired data, the stress strain curves were created. From the stress-strain curves the average compression strength and the energy absorption by volume for $4 \%, 25 \%$ and $50 \%$ strain were obtained. The compressive stress was defined as:

$$
\sigma=\frac{F}{A \times P_{\text {actual }}}
$$

$\mathrm{F}$ is the compressive load, $\mathrm{A}$ is the sample base area and $\mathrm{P}_{\text {actual }}$ is the actual porosity of aluminium foam after the sintering process. The average value of stress in stress-strain curve from yield point up to the onset of densification was assigned to the plateau stress. The actual porosity $\mathrm{P}_{\text {actual }}$ was calculated from Eq.(3), where $\varrho_{a c t u a l}$ is the density of final EDM processed aluminum foam which was calculated by dividing the mass by the volume; and $\varrho_{A 1}$ is the density of aluminium.

$$
P_{\text {actual }}=1-\frac{\rho_{\text {actual }}}{\rho_{A l}}
$$

\section{RESULTS AND DISCUSSION}

\section{Foaming Efficiency Results}

$\square$

rom the foaming analysis results, the following remarks were drawn. Firstly, it should be noted that all the precursors with the aluminium flakes collapsed just after the extrusion from the die. Hence, the specimens with the aluminium flakes were rejected from the foaming stage. As it can be seen from the foaming efficiency - compaction pressure diagram (Fig.5b) (resulted from the $\mathrm{P}_{\mathrm{f}-\mathrm{t}}$ diagrams) the porosity tends to grow by increasing the compaction pressure but stays stable for pressures of $700 \mathrm{MPa}$ and higher. As it is observed by juxtaposing the data obtained from the high definition camera, the specimens with low compaction pressures (200 to $450 \mathrm{MPa}$ ) were unable to integrate the hydrogen of the decomposed $\mathrm{TiH}_{2}$ and as shown in Figs.6(a,b) bursts of hydrogen were emitted. More specifically, the specimens with $200 \mathrm{MPa}$ compaction pressure created only one large burst of hydrogen and only a minor foaming stage was observed, when on the other side the specimens with $450 \mathrm{MPa}$ compaction pressure presented many small bursts at high rate that affected 
the final foaming efficiency of the foams. For compaction pressures of $700 \mathrm{MPa}, 900 \mathrm{MPa}$ and $1200 \mathrm{MPa}$ only few sporadic hydrogen bursts were observed, and the foaming efficiency was kept stable at high values.

The foaming efficiency-foaming temperature diagram (obtained from the corresponding $\mathrm{P}_{\mathrm{ft}-\mathrm{t}}$ diagrams) illustrated that by increasing the foaming temperature the maximum porosity scales up (Fig.5c). For sintering temperatures below the aluminium melting point, a minor foaming stage was observed. The maximum foaming values and foaming efficiencies were observed for $750{ }^{\circ} \mathrm{C}$ and $800{ }^{\circ} \mathrm{C}$ foaming temperatures. Specifically, the specimens with $800{ }^{\circ} \mathrm{C}$ sintering temperature introduced a slightly higher foaming efficiency and a higher foaming rate but collapsed sooner than the specimens with $750^{\circ} \mathrm{C}$ (Fig.5a). All the foamed specimens with the fine aluminium powder presented $15-25 \%$ increased foaming efficiency from the corresponding ones with the coarse aluminium powder. Figs.7(a-d) illustrate representative specimens during their foaming peak.
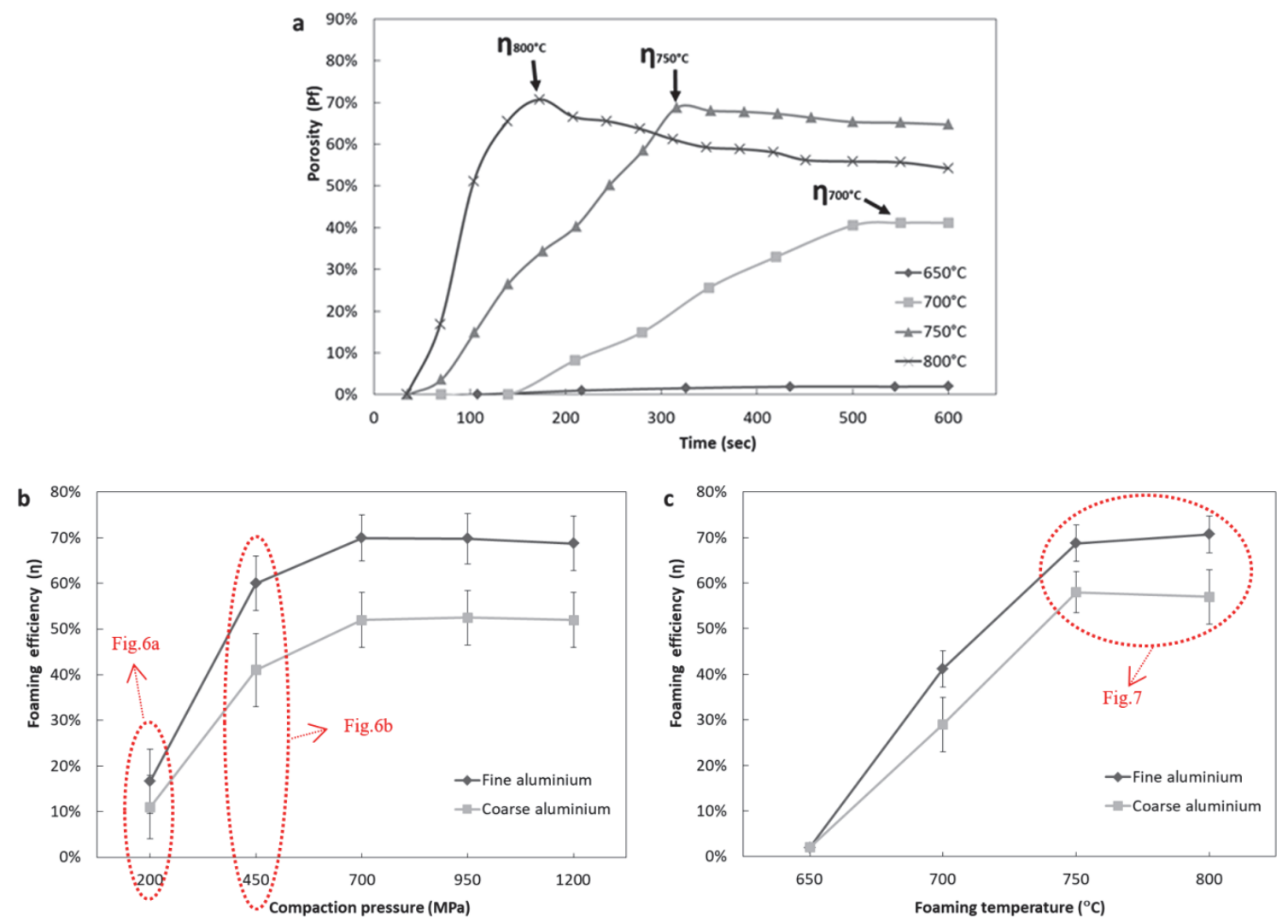

Figure 5: (a) Porosity vs. time for various foaming temperatures (specimens with $700 \mathrm{MPa}$ compaction pressure and fine aluminium powder); (b) foaming efficiency vs. compaction pressure for fine and coarse aluminium powder (specimens with $800{ }^{\circ} \mathrm{C}$ foaming temperature), c) foaming efficiency vs. foaming temperature for fine and coarse aluminium powder (compaction pressure: $700 \mathrm{MPa}$ ).
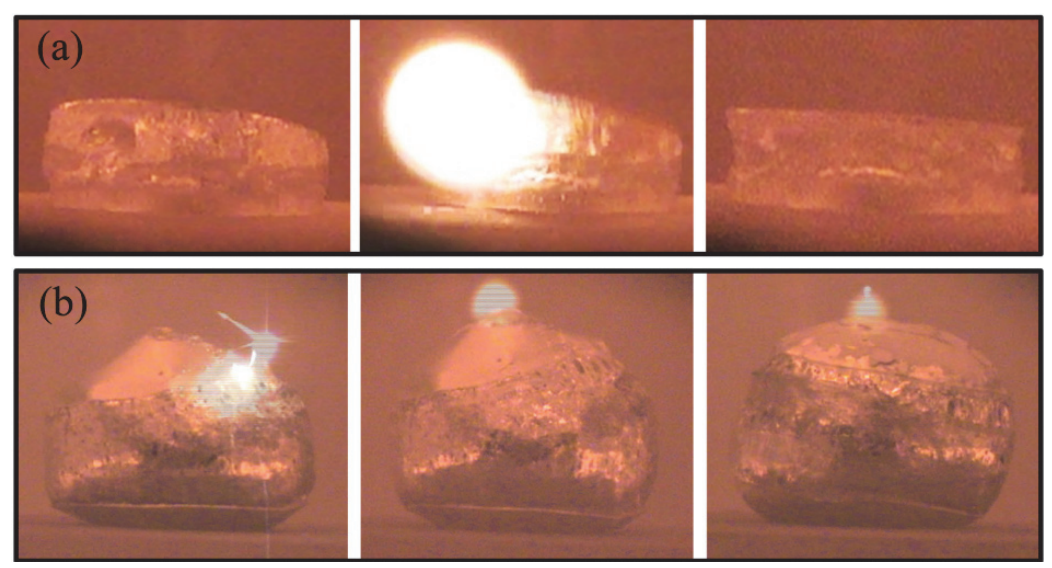

Figure 6: Images of specimens emitting bursts of hydrogen due to insufficient green density: (a) specimen with $200 \mathrm{MPa}$ compaction pressure; (b) specimen with $450 \mathrm{MPa}$ compaction pressure. 

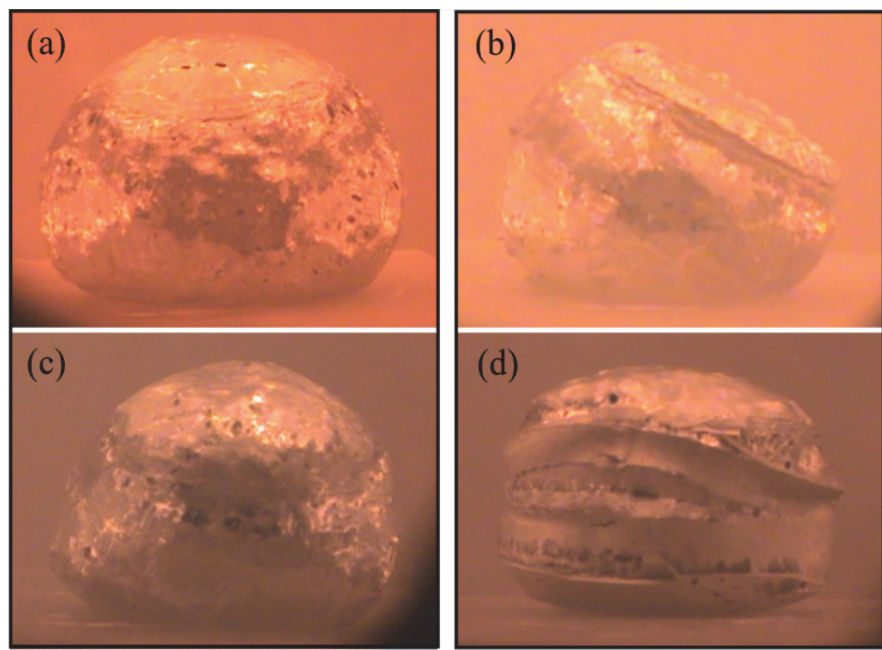

Figure 7: Representative specimens during their foaming peak. Specimens' parameters: (a) $\left(800^{\circ} \mathrm{C} / 700 \mathrm{MPa} /\right.$ fine powder), (b) (800 ${ }^{\circ} \mathrm{C} /$ $700 \mathrm{MPa} /$ coarse powder); (c) $\left(750^{\circ} \mathrm{C} / 700 \mathrm{MPa} /\right.$ fine powder $)$, d) specimen parameters $\left(750^{\circ} \mathrm{C} / 700 \mathrm{MPa} /\right.$ coarse powder $)$.

The foaming process is developed in two stages. The first stage corresponds to the material growing in the solid and semisolid state (before liquidus temperature). This stage starts from the beginning of the foaming stage and ends close to the higher peak of the porosity-time diagram [14]; the peak that also corresponds to the foaming efficiency $(\eta)$. The second stage takes place above the liquidus temperature, after the material has exceeded its melting point. Fig.8 illustrates the first stage of foaming process of the specimen with fine aluminium powder and $800^{\circ} \mathrm{C}$ foaming temperature; which introduced the highest foaming efficiency. The figure embedded in Fig.9 illustrates the pore morphology of the same specimen. The pore structure is characterized by non-interconnected cellular morphology and dense struts. The median pore diameter of foamed samples was close to $2 \mathrm{~mm}$ with pores ranging from 0.5 to $7 \mathrm{~mm}$ (Fig.9).

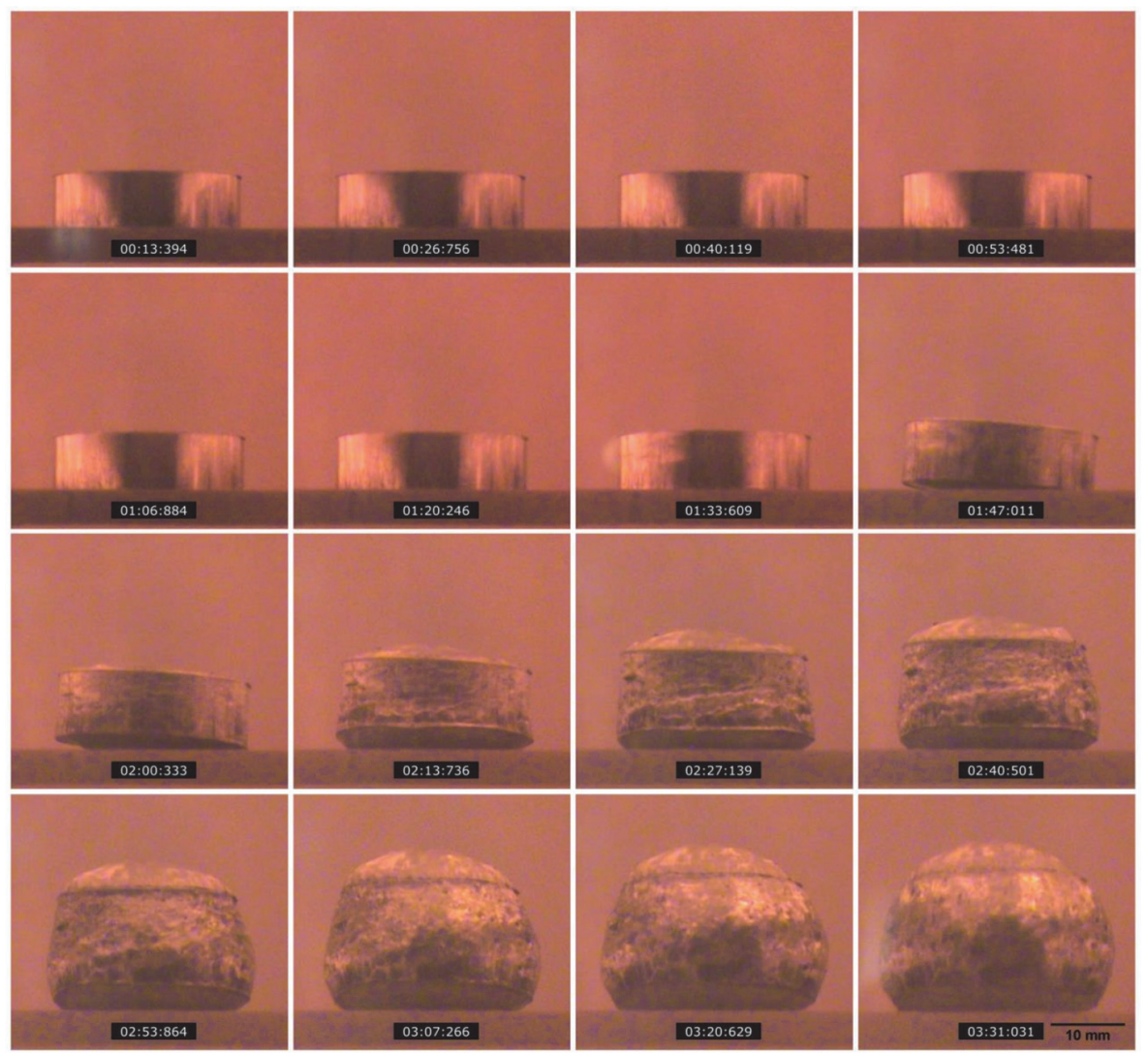

Figure 8: First foaming stage of the specimen with the higher foaming efficiency. 


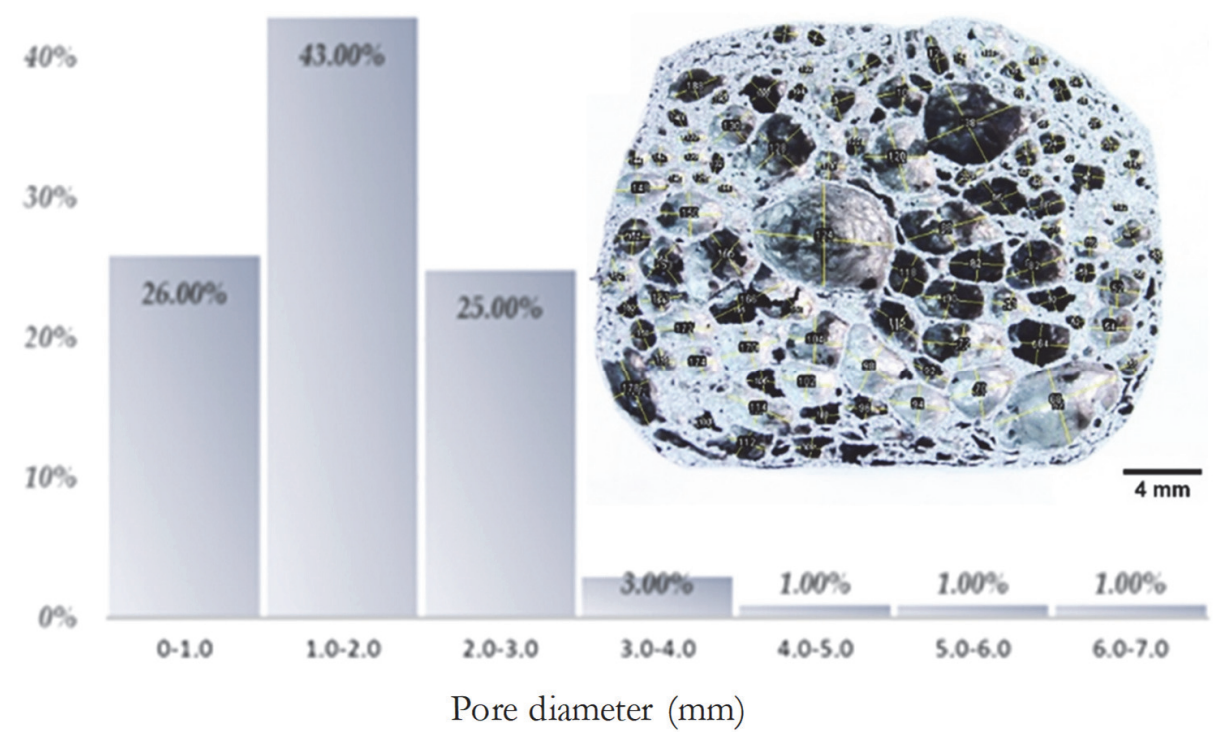

Figure 9: Pore diameter distribution for a specimen with fine aluminium powder and $800^{\circ} \mathrm{C}$ foaming temperature at the maximum porosity. In the embedded figure a typical cross section is shown.

\section{Compressive Tests Results}

The specimens with $800^{\circ} \mathrm{C}$ foaming temperature were chosen to be further investigated by compressive tests due to higher foaming efficiency they exhibited. The tests were performed on those foamed specimens in order to investigate their stressstrain curve (Figs.10(a,b)). The curves were characterized by: (i) the initial elasto-plastic deformation (up to 1-2\% of strain) where partially reversible cell walls bending occurs, (ii) a deformation plateau with a positive slope where cell walls buckle, yield and fracture and (iii) finally a transition to densification where the cell walls become pressed together and the material attains bulk-like properties. The extended plateau is particularly important for the foam application as an energy absorber. The above response was found consistent with results published in literature $[15,16]$. The plateau region was very smooth and showed no oscillations which are typically associated with local failure of cells walls. Furthermore, no upper (UYS) and lower yield stress (LYS) were observed. This can be attributed to the uniform pore distribution of the porous structure. In order to investigate the elastic region more precisely, the elastic region was isolated and focused from the stress-strain curve. The compression strength (at the beginning of the plateau with the positive slope) was $5 \mathrm{MPa}$ and the stress variations in the elastic regime were found to be nearly linear (Fig.10a). Finally, the foam at $25 \%$ and $50 \%$ strain absorbed $1.57 \mathrm{KJ} / \mathrm{dm}^{3}$ energy with a $9.46 \mathrm{MPa}$ plateau, and $5.91 \mathrm{KJ} / \mathrm{dm}^{3}$ energy with a $28.66 \mathrm{MPa}$ plateau respectively (Fig.10c).

(a)

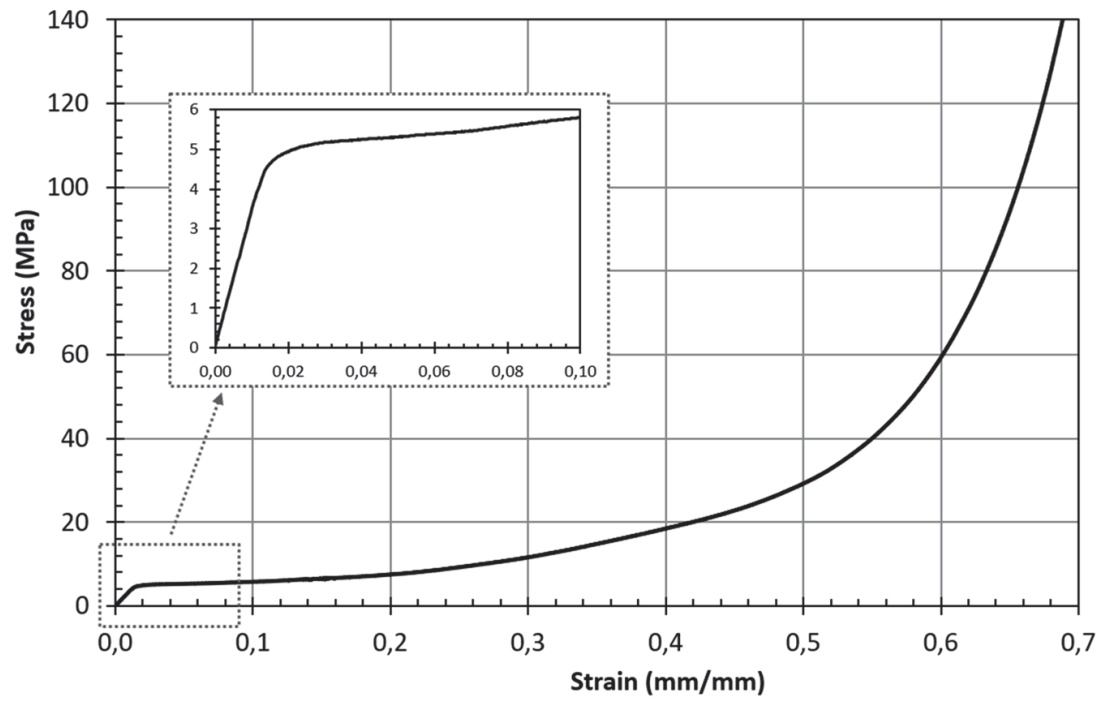

(b)

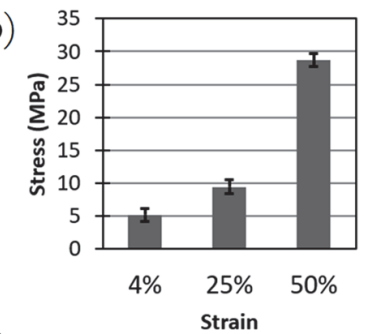

(c)

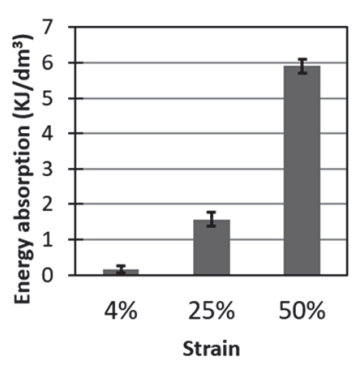

Figure 10: a) Compression stress-strain response, b) Average compression strength and c) energy absorption by volume for $4 \%$, $25 \%$ and $50 \%$ strain (obtained from six individual compression experiments). 


\section{CONCLUSIONS}

$\mathrm{W}$

hile aluminium foams were manufactured using powder metallurgy route with gas releasing particles, the effect of aluminium powder morphology, precursor compaction pressure and foaming temperature were examined. The porosity-time $\left(\mathrm{P}_{\mathrm{f}_{-}}\right)$and the foaming efficiency $(\eta)$ diagrams were obtained. Furthermore, the foams with the parameters resulting to the highest foaming efficiency were subjected to compaction tests.

Concerning the powder morphology, it was concluded that in all tests the foams with the fine aluminium powder exhibited higher foaming efficiency than the foams with coarse aluminium powder. The precursors with aluminium flakes collapsed just after the extrusion from the die.

As far as it concerns the compaction pressure/foaming temperature, the highest foaming efficiency was observed for precursors with compaction pressures higher than $700 \mathrm{MPa}$ and high foaming temperatures of $750{ }^{\circ} \mathrm{C}$ and $800{ }^{\circ} \mathrm{C}$. The specimens with $800{ }^{\circ} \mathrm{C}$ sintering temperature introduced a slightly higher foaming efficiency and foaming rate but collapsed sooner than the specimens with $750^{\circ} \mathrm{C}$.

The compression tests with the specimens with the parameters that resulted to the higher foaming efficiency provided stress-strain curves characterized by the typical initial elastic response, followed by a deformation plateau with a positive slope and finally a transition to densification. The plateau region was very smooth and showed no oscillations which are typically associated with local failure of cell walls. The compression strength at the beginning of the plateau region was 5 $\mathrm{MPa}$ and the stress variations in the elastic regime were found to be nearly linear.

\section{REFERENCES}

[1] Gibson, L. and Ashby, M. (1997). Cellular Solids, Structure and Properties, 2nd ed. Cambridge University Press, UK.

[2] Ashby, M., Evans, A., Fleck, N., Gibson, L., Hutchinson J., Wadley, H. (2000). Metal Foams: A Design Guide. Butterworth-Heinemann, USA.

[3] Banhart, J. (2001). Manufacture, characterization and application of cellular metals and metal foams, Progress in Materials Science 46, 559-632.

[4] Michailidis, N., Stergioudi, F., Tsouknidas, A. (2011). Deformation and energy absorption properties of powdermetallurgy produced Al foams, Materials Science and Engineering: A 528,7222-7227.

[5] Laughlin, D., Hono, K. (2013). Porous Metals. Physical Metallurgy, 5th ed., Elsevier, Amsterdam.

[6] Salimon, A., Brechet, Y., Ashby, M., Greer, A. (2005). Potential applications for steel and titanium metal foams, Journal of Materials Science 40, 5793-5799.

[7] Davies, G., Zhen, S. (1983). Review Metallic foams: their production, properties and applications, Journal of Materials Science 18, 1899-1911.

[8] Allen, B., Sabroff, A. (1963). Method of making foamed metal. US Patent 3,087,807.

[8] Duarte, I., Banhart, J. (2000). A study of aluminium foam formation - kinetics and microstructure, Acta Materialia 48(9), 2349-2362.

[9] Baumgärtner, F., Duart, I., Banhart, I. (2000). Industrialization of powder compact foaming process, Advanced Engineering Materials 2, 168-174.

[10] Shiomi, M., Imagamab, S., Osakada, K., Matsumoto, R. (2010). Fabrication of aluminium foams from powder by hot extrusion and foaming. Journal of Materials Processing Technology 210, 1203-1208.

[11] Kitazono, K., Sato, E., Kuribayashi, K. (2003). Novel manufacturing process of closed-cell aluminum foam by accumulative roll-bonding, Scripta Materialia 50, 495-498.

[12] Papantoniou, I., Kyriakopoulou, E., Pantelis, D., Athanasiou-Ioannou, A., Manolakos, D. (2018). Manufacturing process of AA5083/nano- $\gamma \mathrm{Al} 2 \mathrm{O} 3$ localized composite metal foam fabricated by friction stir processing route (FSP) and microstructural characterization, Journal of Materials Science 53, 3817-3835.

[13] Lazaro, J., Solorzano, E., de Saja, J.A. (2012). Early anisotropic expansion of aluminium foam precursors, J Mater Sci 48, 5036-5046.

[14] Strano, M., Pourhassan, R., Mussi, V. (2013). The effect of cold rolling on the foaming efficiency of aluminium precursors, Journal of Manufacturing Processes 15, 227-235.

[15] Shim, C., Yun, N., Yu, R., Byun, D. (2012). Mitigation of Blast Effects on Protective Structures by Aluminum Foam Panels, Metals 2(2), 170-177. 